\title{
Study of active neighborhoods in Detroit (StAND): study protocol for a natural experiment evaluating the health benefits of ecological restoration of parks
}

Amber L. Pearson ${ }^{1 *}$, Karin A. Pfeiffer ${ }^{2}$, Joseph Gardiner ${ }^{3}$, Teresa Horton ${ }^{4}$, Rachel T. Buxton ${ }^{5}$, Ruth F. Hunter ${ }^{6}$, Victoria Breeze ${ }^{1}$ and Thomas McDade ${ }^{4}$

\begin{abstract}
Background: Individuals living in deprived inner cities have disproportionately high rates of cancers, Type 2 diabetes and obesity, which have stress- and physical inactivity-related etiologies. This study aims to quantify effects of ecological park restoration on physical activity, stress and cardio-metabolic health outcomes.

Methods: The Study of Active Neighborhoods in Detroit is a quasi-experimental, longitudinal panel natural experiment with two conditions (restored park intervention (INT) and control (CNT)) and annual measurements at baseline and 3years post-restoration. Individuals (sampled within $500 \mathrm{~m}$ of an INT/CNT park) serve as the unit of analysis. Restoration ( $n=4$ parks) involves replacing non-native plants and turf with native plants; creating trails; posting signage; and leading community stewardship events. The CNT condition $(n=5)$ is an unmaintained park, matched to INT based on specified neighborhood conditions. Recruitment involves several avenues, with a retention goal of 450 participants. Park measures include plant/avian diversity; usage of the park (SOPARC); signs of care; auditory environment recordings; and visual greenness using 360 imagery. Health outcomes include device-based physical activity behavior (primary outcome); salivary cortisol (secondary outcome); and several downstream health outcomes. Exposure to the INT will be assessed through visual contact time and time spent in the park using GPS data. Changes in health outcomes between years and INT versus CNT will be tested using generalized linear (mixed) models.
\end{abstract}

Discussion: Our study will examine whether restored urban greenspaces increase physical activity and lower stress, with public health planning implications, where small changes in neighborhood greenspaces may have large health benefits in low-income neighborhoods.

Study Registration: Registration: OSF Preregistration registered March 31, 2020. Accessible from https://osf.io/surx7. Keywords: Low-income, Built environment, Greenspace, Urban planning, Physical activity, Stress, Green exercise

\footnotetext{
*Correspondence: apearson@msu.edu

${ }^{1}$ Department of Geography, Environment and Spatial Sciences, Michigan

State University, 673 Auditorium Road, East Lansing, MI 48824, USA

Full list of author information is available at the end of the article
}

(c) The Author(s). 2020 Open Access This article is licensed under a Creative Commons Attribution 4.0 International License, which permits use, sharing, adaptation, distribution and reproduction in any medium or format, as long as you give appropriate credit to the original author(s) and the source, provide a link to the Creative Commons licence, and indicate if changes were made. The images or other third party material in this article are included in the article's Creative Commons licence, unless indicated otherwise in a credit line to the material. If material is not included in the article's Creative Commons licence and your intended use is not permitted by statutory regulation or exceeds the permitted use, you will need to obtain permission directly from the copyright holder. To view a copy of this licence, visit http://creativecommons.org/licenses/by/4.0/ The Creative Commons Public Domain Dedication waiver (http://creativecommons.org/publicdomain/zero/1.0/) applies to the data made available in this article, unless otherwise stated in a credit line to the data. 


\section{Background}

Individuals living in socioeconomically deprived inner cities have disproportionately high rates of obesity, Type 2 diabetes, cancer and cardio-metabolic conditions, all of which have stress- and physical inactivityrelated etiologies [1-14]. The cost of these diseases is enormous, where the direct annual medical costs for obesity exceed \$300b [15], and societal tolls include declining or stagnating life expectancy, particularly in low-income communities [16]. Low-income neighborhoods experience dual risks, whereby physical activity (PA) levels are low and stress levels are high $[17,18]$. Stress and physical inactivity can both lead to downstream inflammatory changes that alter body composition and metabolic and immune functions linked to chronic disease [19-22]. Studies underscore the twinned benefits of weight management and lowered stress that engaging in PA confers [23]. Lower stress, regardless of PA, assists with sustained weight loss [24] and improved cardio-metabolic health [25], making it an attractive goal for health benefits.

To induce change in PA and stress on a population level, researchers and city planners are exploring features of the built environment, such as greenspace (e.g., parks), that may promote healthy lifestyles [26, 27]. Parks serve as places to engage in PA in direct contact with nature - called 'green PA' - which has been shown to lower anxiety [28] and perceived stress $[29,30]$ over and above the effects of indoor PA [23] or outdoor PA without greenery [31]. In addition, cross-sectional research indicates that passive exposure to greenspace (e.g., visual, as in the sight of plants and trees, and auditory, as in birdsong) may lower stress [32, 33]. However, not all residents living near parks visit the parks or engage in PA, and, empirically, the relationship between neighborhood greenspace and PA is inconsistent (for a review [34]). Even so, greener neighborhoods consistently predict lower obesity rates across age groups and rural/urban settings [35-41]. One possible explanation for these findings is that healthier people simply choose to live in greener areas. Yet another possible explanation is that the greenness-obesity relationship is influenced not only by PA but by stress reduction.

To address these knowledge gaps, we designed the Study of Active Neighborhoods Detroit (StAND) to utilize a natural experiment (not a behavioral intervention) to illuminate the causal health effects of greenspace. We integrate leading-edge geospatial techniques to assess individual-level exposure to greenspace with longitudinal evaluation of device-based measures of PA and biomarkers of stress and cardio-metabolic health in low-income, predominantly African American individuals living in neighborhoods in Detroit, Michigan U.S.A.

\section{Objectives}

The aims of StAND are to observe the effects of ecological restoration of parks on PA, stress and cardiometabolic health outcomes from baseline through threeyears post restoration using a quasi-experimental design. The hypotheses are:

\section{Hypothesis 1}

Compared to participants in control (CNT) park neighborhoods, participants in intervention (INT) park neighborhoods will have increased PA levels at three-years post-restoration.

\section{Hypothesis 2}

Compared to participants in CNT park neighborhoods, participants in INT park neighborhoods will have increased levels of 'green PA' at three-years postrestoration.

\section{Hypothesis 3}

Across both INT and CNT parks, the quality of visual and auditory exposures (positive and negative) will affect PA levels.

\section{Hypothesis 4}

Compared to participants in CNT park neighborhoods, participants in INT park neighborhoods will have lower stress levels as indexed by measures of cortisol, perceived stress, and anxiety at three-years post-restoration.

\section{Hypothesis 5}

Participants with higher levels of PA and 'green PA' will have lower stress.

\section{Hypothesis 6}

The quality of visual and auditory exposures (positive and negative) will affect stress levels.

\section{Hypothesis 7}

Compared to participants in CNT park neighborhoods, participants in INT park neighborhoods will have improved glycated hemoglobin A1C (A1C) and C-reactive protein $(\mathrm{CRP})$ at three-years post-restoration.

\section{Hypothesis 8}

Compared to participants in CNT park neighborhoods, participants in INT park neighborhoods will have lower blood pressure, body mass index (BMI), and hip-to-waist ratios at three-years post-restoration.

\section{Methods}

\section{Design}

The overall design of StAND is a four-year quasiexperimental, natural experiment, with two conditions 
(INT and CNT), four measurement occasions, and individual-level measurement of exposures and outcomes (see Fig. 1 for a conceptual diagram for the study). Four INT parks were selected by Detroit Audubon and five comparable CNT parks were selected, based on size, existing trees/plants, and proximity to other bird habitats. All adults (i.e. aged $\geq 18$ years) living in a CNT or INT park neighborhood (defined in the following text) were invited to participate. Baseline $(t=0)$ and three annual measurements $(t=1$ to $t=3)$ post-restoration will be conducted on participating individuals with the intention of having a longitudinal panel study design. However, we considered sampling alternatives depending on attrition, as others studies have done [42]. If attrition is higher than expected $(>25 \%$ at $t=1$ ), then additional participants will be recruited at each time point, yielding a repeated crosssectional design, with a nested panel. If assessments at certain time points are missing within the panel for some participants, we will assume that data from our unbalanced panel is missing at random.

The study was approved by the Michigan State University's Institutional Review Board (IRB Approval \#STUDY00000587; date 03/21/2019). The study was registered with OFS (osf.io/surx7) and successfully tested in a pilot study (Pearson AL, Clevenger K, Horton TH, Gardiner J, Asana V, Dougherty B, et al: Feelings of safety during daytime walking: Associations with mental health, physicial activity and cardiometabolic health in two high vacancy, low-income neighborhoods in Detroit, Michigan, in review) [43]. The protocol was completed using the TREND guidelines [44].

\section{Participants}

Participants are adults who reside in a study park's zone of influence, which is deemed to be $0.5 \mathrm{~km}(0.31 \mathrm{mi})$, which is an approximate 15-min walk to the park and also a reasonable maximum distance for hearing birdsong in an urban setting [45]. Participants will be recruited from within a 16 -cell grid $\left(120 \mathrm{~m}^{2} /\right.$ cell $)$ around each park. Thus, the unit of measurement is the individual, but the unit of assignment-to-intervention is neighborhood. We conducted a pilot study in two neighborhoods in 2018 ( $n=67$ participants enrolled) and received funding at the end of the summer in 2019, yielding a truncated field season $(n=$ 145 participants). The first full field season for this study will be 2020. To recruit participants, we mail postcards and conduct recruitment activities (e.g., information booths) in each neighborhood. Field staff then visit homes in each study neighborhood to brief potential participants on the study, request participation, and screen for inclusion. We recruit only one English-speaking male or female $(\geq 18 y$ ) without mobility issues per household, which is at the household's discretion. To ensure participant comprehension and confirm contact information, we use an electronic text message to finalize enrollment. Participants are then instructed on the correct usage of the accelerometer (Actigraph GT3X), Global Positioning System (GPS) device (Canmore) and cortisol sample collection and instructed that a study shuttle will take them to their scheduled health appointment in our study office. The target total sample is 450 adults to be recruited and retained. To retain participants, we will employ a set of strategies including: 1) sending holiday cards with neighborhoodlevel results; 2) sending birthday cards; and 3) sending periodic, brief surveys through StANDApp.

\section{Sample size}

Assuming a longitudinal panel design, sample size assessments for the study are based on achieving $82 \%$ power to test the hypotheses. The effect measure is a difference-in-

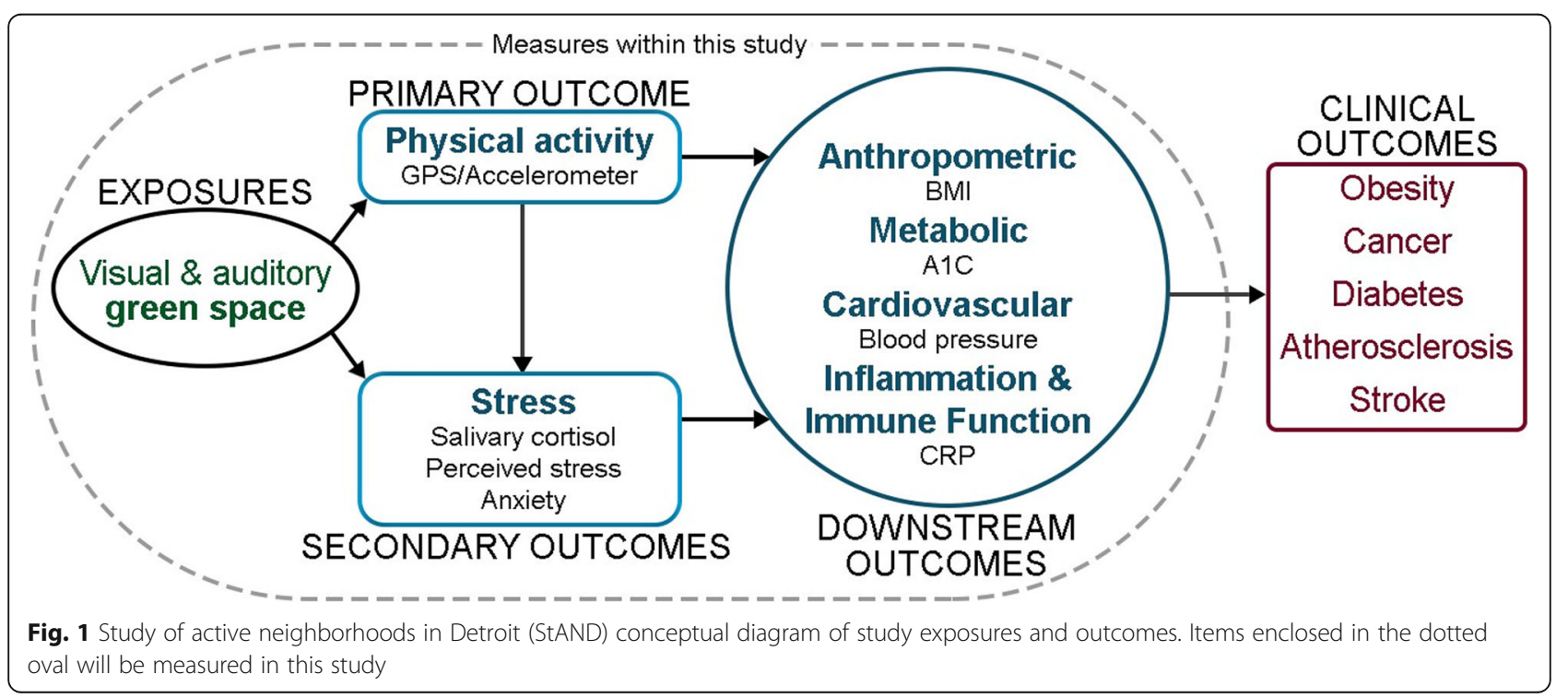


differences (DID) - in hypotheses 1-3, i.e., the expected change in PA from baseline to three-years postrestoration in INT parks compared to the corresponding change in CNT parks. Hypotheses 3-6 concern a DID in stress outcomes. A review of the literature on PA [46] and cortisol [47] suggests an effect size (EF) of 0.35 could be posited. Accordingly, we calculate our sample size requirements to detect an EF of 0.35 or better with $82 \%$ power. Two other design features are: a serial correlation $r$ between repeated measures over time and intra-class correlation (ICC) $\rho$ for clustering within neighborhood parks. In community-intervention studies such as ours, $\rho$ is small [48-51]. Plausible values from the literature and our own experiences, suggest $r \geq 0.35$ and $\rho \leq 0.004$. With a total of nine parks (4 INT, $5 \mathrm{CNT}$ ), we will need a sample of 450 participants, or 50 per park, to detect $\mathrm{EF}=0.35$ with $82 \%$ power, based on a two-sided test at significance level 5\%. Because attrition is expected over the study period, we will recruit a total of 620 participants at $\mathrm{t}=0$ (baseline) to account for attrition of $15 \%$ at $t=1$ and another $10 \%$ at $t=2$ and $5 \%$ at $\mathrm{t}=3$. Our sample size assessment may also be deemed conservative as it does not account for potential influence of fixed covariates, which should increase precision on the intervention effect estimate by reducing residual variance resulting in a positive effect on power.

\section{Intervention and control parks}

Both INT and CNT parks were selected from the same pool of designated 'Community Open Spaces' by the City of Detroit Parks \& Recreation Department (DPRD). These parks are not maintained as traditional parks and are only mowed once annually. From this pool, we selected CNT parks matched to INT parks based on neighborhood conditions: blighted buildings, greenery, vacant lots, major roads, industrial land use, poverty, and violent/property crime.

\section{Intervention description}

To combat problems with severe population decline, abandoned and demolished buildings, and huge numbers of unmaintained parks and empty lots [52], DPRD created an Improvement Plan in 2017 to: 1) improve existing parks; 2) strengthen neighborhoods through parks; and 3) convert open spaces into forest buffers, meadows or urban agriculture. DPRD has now implemented this urban rejuvenation effort in partnership with Detroit Audubon.

By restoring unused parks to meadows with native grasses and wildflowers, Detroit Audubon intends to create what it calls Detroit Bird City, a city-wide habitat corridor to help conserve hundreds of North American bird species that pass through Michigan using the Detroit River as a migration flyway. Detroit Audubon is scheduled to restore these four parks in 2019-2020.
Restorations will include: 1) replacing non-native plant and wildflower species with native species and removing turf and cement; 2) creating trails around each park's perimeter; 3) adding signage in the park about these efforts; conducting 4) avian and plant biodiversity surveys at each park and 5) guided bird watching walks; and 6) holding community meetings and an annual stewardship event led by Detroit Audubon and DPRD to promote engagement. Each park intervention will be rolled out over a six-month period, including all the activities. Time from restoration to grassland maturation is estimated to be three years. Audubon, in partnership with residents (receiving a paid incentive for maintenance), will keep up these nature areas following restoration.

\section{Control description}

In June 2018, we conducted extensive inventories of all nine parks at baseline, evaluating the following: bird species, plant species, and maintenance and usage of parks. Each park had 8-20 bird species, with American Robin and European Starling the most common. Plant diversity was low, with many invasive species and turf grass. Broken cement and signs of dumping were common. Only one park was observed to be used by park-goers (see Fig. 2 for examples of current park conditions). We expect the CNT parks in this project to continue these conditions and to remain unmaintained (only mowed once annually) during the duration of the study.

\section{Risk of bias assessment}

This study employs the Risk Of Bias In Non-randomized Studies of Interventions (ROBINS-I) tool [53] to assess risk of bias for the pre-intervention components. Specifically, we aimed to reduce bias due to confounding by: i) including a suite of potential individual-level confounders in our survey instrument (detailed below); ii) matching INT and CNT neighborhoods based on baseline area-level factors which may influence both the outcomes and the exposures of interest (detailed above); and iii) consideration of potential co-interventions that might occur (that are related to receiving the intervention and the outcomes). The potential for the intervention to lead to gentrification was identified. Specific items in the surveys will measure perceptions of gentrification and median home price in each study neighborhood will be quantified using publically available data from Redfin, a national real estate brokerage, for each time point. At the time of the intervention, bias in the classification of the intervention will be minimized by collecting objective data on: park usage, plant species, bird species, greenness and signs of care. Postintervention bias will be assessed at the conclusion of the study. 

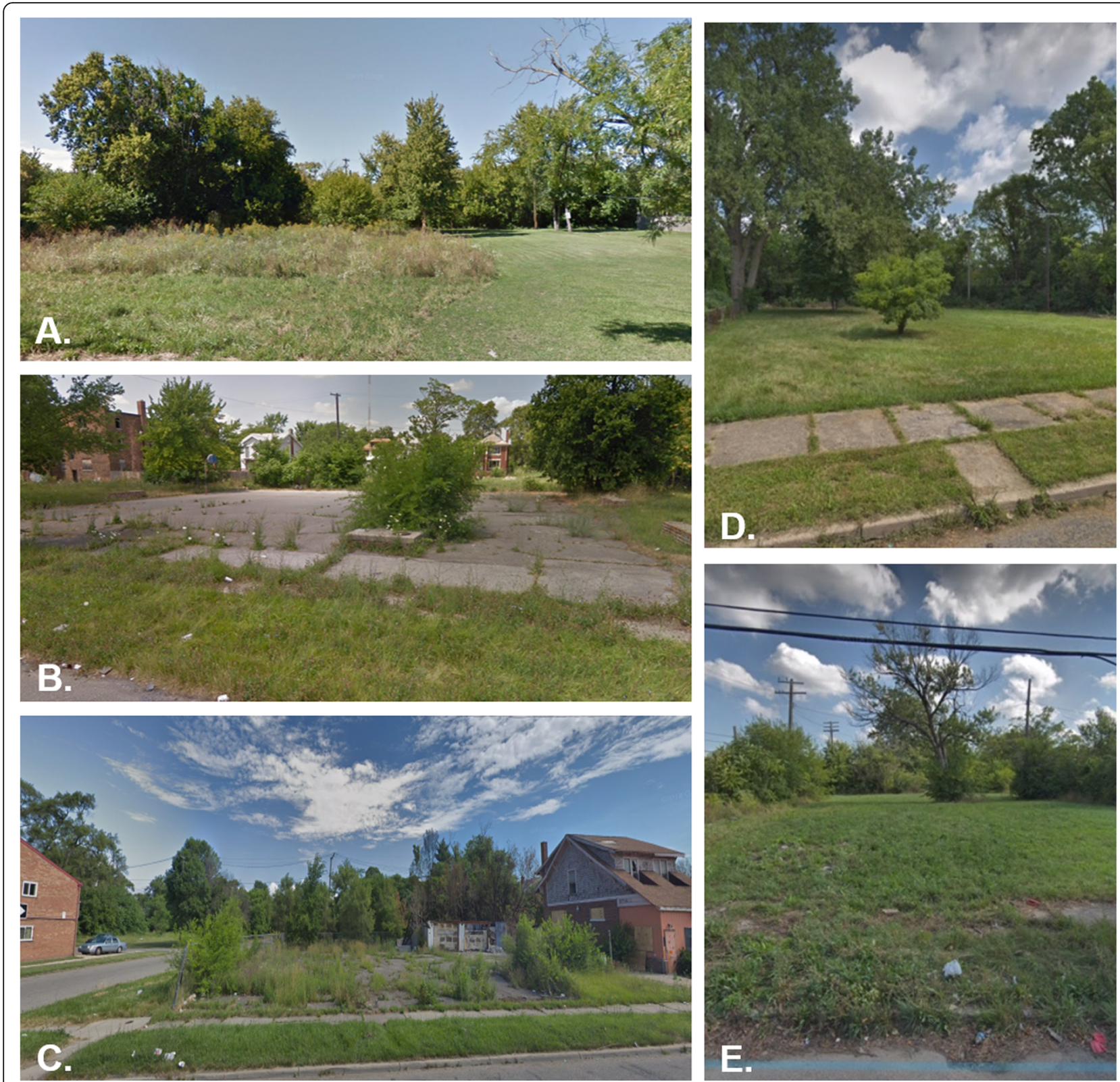

Fig. 2 Examples (a-e) of current conditions in typical participating parks in Detroit, Michigan, U.S.A. Source: Google Street View

The participants and the study staff collecting outcome data will be blinded to the condition assignment. This will be accomplished by referring to neighborhoods using a three-letter code and restriction of information about the intervention locations. We will assess blinding at the end of each field season by asking staff which neighborhoods they believe are receiving the intervention. Success will be determined as either i) a majority of "don't know" responses; or ii) a balance between correct and incorrect responses. Because this is a natural experiment and the researchers have no control over whether the intervention is carried out completely in all locations and to what degree the intervention is discussed throughout the neighborhoods, assessment of blinding of participants is not appropriate.

\section{Measurement protocol}

All items to be assessed are in Table 1 and include both individual and area-level measures. At recruitment, accelerometers (Actigraph GT3X) and GPS devices (Canmore) on an elastic belt and saliva collection kits will be distributed, and data will be collected for the following week. For subsequent time points, participants will be phoned to arrange an equipment delivery time and schedule a health appointment. Participants will be reminded via StANDApp (detailed below) and/or text to 
Table 1 Tools, scale of measurement, and measurements that will be obtained annually 2019-2024. Individual-level refers to measurements collected from individual household participants and area-level refers to measurements collected within and at some points around a park

\begin{tabular}{|c|c|c|}
\hline Tool/Nariable & $\begin{array}{l}\text { Individual or } \\
\text { area-level }\end{array}$ & Measures obtained \\
\hline Survey & Individual & $\begin{array}{l}\text { Demographics, perceptions of } \\
\text { neighborhoods, disease and } \\
\text { medication history, diet, perceived } \\
\text { stress score, anxiety and depression } \\
\text { symptoms, nature-relatedness, per- } \\
\text { ceived safety, acute illness }\end{array}$ \\
\hline $\begin{array}{l}\text { Physical activity } \\
\text { (PA) }\end{array}$ & Individual & $\begin{array}{l}\text { Total activity counts, Moderate-to- } \\
\text { vigorous PA, when combined with GPS } \\
\text { - green PA }\end{array}$ \\
\hline GPS & Individual & $\begin{array}{l}\text { Time spent in park, time spent in view } \\
\text { of park, when combined with PA - } \\
\text { green PA }\end{array}$ \\
\hline Cortisol samples & Individual & $\begin{array}{l}\text { Total concentration, slope of cortisol } \\
\text { from waking to evening }\end{array}$ \\
\hline $\begin{array}{l}\text { Dried blood } \\
\text { spots }\end{array}$ & Individual & C-reactive protein \\
\hline Finger-stick A1C & Individual & Hemoglobin A1C levels \\
\hline Plant surveys & Area & $\begin{array}{l}\text { Plant diversity of park, invasive species } \\
\text { versus native species }\end{array}$ \\
\hline SOPARC & Area & Usage of park \\
\hline Signs of care & Area & Maintenance level of park \\
\hline Bird surveys & Area & Bird diversity of park \\
\hline 360 imagery & Area & $\begin{array}{l}\text { Greenness of park, negative visual } \\
\text { exposures, signs of disorder }\end{array}$ \\
\hline $\begin{array}{l}\text { AudioMoth } \\
\text { acoustic } \\
\text { recorders }\end{array}$ & Area & $\begin{array}{l}\text { Bird species, insects, sound diversity, } \\
\text { noise }\end{array}$ \\
\hline Weather station & Area & Daily precipitation, high temperature \\
\hline
\end{tabular}

wear the elastic belt and to collect saliva samples. Participants will also take a paper survey at home. Participants will return the equipment, survey and saliva kits at the health appointment or, if they forget an item, will schedule a time to return the item(s) in order to receive the compensation voucher.

At the health appointment, field staff will collect anthropometrics and dried blood spot (DBS) samples, measure $\mathrm{A} 1 \mathrm{C}$ using test strips, and retrieve equipment and cortisol samples. All health data will be entered and then shared with each participant via a health results sheet, which includes resources for free or low-cost healthcare in Detroit.

\section{StANDApp smartphone app}

In partnership with MEI Research Ltd., we have developed a secure mobile app for all study communication, scheduling, and retaining survey deployment. MEI's PiLR [54] system will allow for the deployment of surveys as a form of monthly contact from the study team to increase retention, sharing health results with each participant, and reminders about health appointments, charging units and wearing belts and taking cortisol samples. Based on pilot work, we determined that some participants may be reticent to use this application on their mobile phone. Accordingly, we will use the app on a voluntary basis. All reminders will also be sent by text message, negating the requirement that all participants use the app.

\section{Physical activity (primary outcome) measured using accelerometry}

PA and sedentary behavior are measured using the ActiGraph accelerometer (ActiGraph model GT3X; Pensacola, FL). The ActiGraph is a triaxial accelerometer that measures acceleration in three planes of motion. Accelerometers capture and filter acceleration signals that are digitized and recorded as count values that are stored in investigator-defined intervals. Raw data are stored and may also be used for analyses.

The accelerometers will be worn on an elastic waistband, placed at the right hip, for all waking hours over seven days at each of the study's four measurement time points (all during the summer or early autumn). Data will be collected in raw mode $(30 \mathrm{~Hz})$ and aggregated to 1 -min values for analyses. The primary outcome is total PA counts per week, which has been associated with cardio-metabolic outcomes and biomarkers [22]. Analyses will also include number of minutes spent at given PA intensity levels using cut-points of Freedson et al. $(\geq 1952 \mathrm{cpm})$ for moderate-to-vigorous intensity PA and Matthews et al. $(<100 \mathrm{cpm})$ for sedentary behavior, with light PA as $100-1951 \mathrm{cpm}[55,56]$. We will also explore PA intensity levels using vector magnitude cutpoints [57]. In addition, these measures will be stratified by whether the PA occurred in the study park, in any greenspace, or elsewhere (based on GPS data). This will provide an indication of the proportion of 'green PA' from total PA. Periods of $60 \mathrm{~min}$ or more of continuous zeroes are considered non-wear times and not included in the calculation of total wear time. To be included, we will require $\geq 4$ days of PA data (wear time $\geq 8-10 \mathrm{~h} /$ day) per time point [58]. If high levels of missing data exist, imputation strategies will be utilized. PA data will be collected at the same time of year (summer months only) to account for seasonality.

\section{Mobility and park contact measured using GPS data}

GPS units (Canmore) will be worn for one week, on an elastic belt with an accelerometer. At the end of the week of observation, data will be downloaded. To calculate the amount of time spent in 'green PA', these data will be linked with accelerometer data using time. Accelerometer data are then restricted using a threshold for 
PA and lux ( $>400)$. Speed is calculated and data are further restricted by excluding speeds $>25 \mathrm{kmph}$. This results in total green PA. We will also use GPS data to calculate the actual contact time spent within view of the park [59] and usage of park. To calculate time spent within view of park, we will create 'viewsheds' around each park to determine all possible viewpoints from which the park can be seen, accounting for obstacles such as buildings, as we have done previously [60, 61]. To calculate usage of park, all GPS points located within $10 \mathrm{~m}$ of the park boundaries will be compiled to calculate time spent in park.

\section{Stress measures (secondary outcome)}

We will measure salivary cortisol, perceived stress and anxiety. Stress alters the dynamics of the diurnal rhythm of cortisol secretion, and people who are chronically stressed exhibit lower morning and higher evening concentrations, yielding flattened slopes [19, 20, 47, 62-67]. Samples will be collected using the passive drool method [68] at waking, and 12-h after waking to permit calculation of time point concentrations and the slope of cortisol from waking to evening. The saliva collection kit contains collection supplies, a response sheet and reminder instructions. Participants will be reminded to take and freeze samples at designated times the day before their scheduled health appointment via StANDApp and/or text. Participants will also be reminded to bring kits to their appointment the next day $[69,70]$. In the field, samples will be stored in a manual-defrost freezer and shipped on dry ice (once per measurement period) to Northwestern University's Laboratory for Human Biology Research where they will be thawed, centrifuged and the supernatant aliquoted into replicate samples in smaller tubes and analyzed in duplicate. Low, medium, and high concentration controls will be prepared in at $t=0$ for use throughout the study to monitor inter-assay variability. Cortisol will be measured using the Salimetrics ELISA kit as per manufacturer's instructions [71].

We will also use two stress indicators via the survey, including: 1) Anxiety and Depression, measured via NIH's Adult PROMIS-29 Profile v2.0 [72, 73]; and 2) the Perceived Stress Scale [74], comprising 10 items (e.g., feeling nervous) measured on Likert-type scale $(0=$ low, $40=$ max stress). The perceived stress scale has been validated in multiple populations, and the face validity and scale content were ranked high with a Kaiser-MeyerOlkin coefficient of 0.82 [75]. The scale's internal consistency reliability was good in multiple languages and convergent validity was supported by expected relationships with other mental health measures, including anxiety and depression [76]. The PROMIS-29's (our measures of anxiety and depressive symptoms) internal consistency for sub-domains has been shown to be high
(Cronbach's $\alpha>0.88$ ), with adequate structural validity for most domains $(\mathrm{CFI}>0.95$, RMSEA < 0.05) [77].

\section{Anthropometric and cardio-metabolic measures (downstream outcomes)}

Cardio-metabolic outcomes will include body mass index (BMI), waist-to-hip ratio, blood pressure, glycated hemoglobin $\mathrm{A} 1 \mathrm{C}(\mathrm{A} 1 \mathrm{C})$ and $\mathrm{C}$-reactive protein (CRP). Height will be measured twice using a stadiometer (SECA Corp). Weight will be measured twice using a scale with bioelectric impedance capability (Tanita TBF300). Waist and hip measurements will be taken twice with a Gulick tape, according to World Health Organization (WHO) procedures [78] and the waist-tohip ratio calculated. Systolic and diastolic blood pressures will be measured as markers of cardiovascular disease (CVD) risk using an automatic upper arm monitor (Omron HEM-711DLX), according to American College of Cardiology recommendations [79]. With the patient seated, two blood pressure measurements will be taken at $30 \mathrm{~s}$ intervals. The average of each set of measurements will be used for height, weight, waist and hip measurements and blood pressure. BMI will be calculated and expressed as $\mathrm{kg} / \mathrm{m}^{2}$. A1C $[8,80]$ will be measured from blood samples collected from finger-tip sticks using portable analyzers and test strips $\left(\mathrm{A} 1 \mathrm{CNow}^{+}\right)$. Participants will be given these results immediately, including normal ranges and recommendations for consulting a physician.

CRP will be measured to indicate chronic inflammation [81-90], associated with obesity, Type 2 diabetes, cancer, and CVD [89, 91-94]. DBS samples will be collected on Whatman 903 Protein Saver Cards [95, 96] from finger sticks following collection of blood for the A1C analyses. DBS serves as the lowest risk, least invasive blood sampling technique [95]. Circulating levels of CRP in young, healthy adults average $0.8 \mathrm{mg} / \mathrm{l}$. Chronic stress induces small changes in the range of $2-5 \mathrm{ng} / \mathrm{l}$ necessitating the use of high-sensitivity assays for CRP [90, 97]. Upon collection of DBS, samples will be transferred to Northwestern University's Laboratory for Human Biology Research where CRP will be eluted from the DBS and assayed using a CRP assay previously validated in their laboratory for use with DBS [84, 97]. To reduce inter-assay variability and improve quality control, all samples will be stored with humidity sponges and oxygen absorbents and frozen $\left(-20^{\circ} \mathrm{C}\right)$ until the final data collection year (2022) and then analyzed concurrently, with no expected degradation.

\section{Survey}

Basic demographic data information (age, sex, ethnicity, employment, household composition, length of residence) will be collected at recruitment or when re- 
contacted at each timepoint. Then, each participant will complete a self-administered paper survey in the privacy of their own home to assess: income, perceptions of the neighborhood [98-102], disease and prescription medication history [103-106], diet [107, 108], perceived stress [74], anxiety and depression symptoms [72, 73] (discussed previously), nature-relatedness [109]; all which were considered potential correlates of device-based PA and stress. Questions about the perceptions of the social and environmental features of neighborhoods have been shown to have moderate to high agreement (rho range = 0.42-0.91) [99]. Family Life, Activity, Sun, Health, and Eating (FLASHE) questions related to diet were reviewed by the scientific experts for consistency with existing, validated measures [108]. The nature-relatedness scale (NR-6) has been shown to demonstrate good internal consistency, temporal stability, and predict happiness, environmental concern, and nature contact [109]. Measures that may serve as confounders include: 1) symptoms of acute illness or infection or prescription medication which could influence biomarker measures; 2) attitudes toward nature using the NR-6, because these may influence behaviors; and 3) perceived safety which may influence stress [110], PA [111, 112], and park usage [113].

\section{Park observations and imagery}

The positive visual exposures of interest include the presence of people using the park, signage, mowing and other signs of care [114], diversity of plants and birds and greenness. Negative visual exposures include the presence of litter, arson, graffiti and broken windows of buildings along the park perimeter (called signs of disorder). We will employ two methods to obtain these data. First, Audubon volunteers will inventory plants in quadrants and count bird species using point counts less than three hours after sunrise, measuring species abundances $[115,116]$. Volunteers will be trained by Audubon, and inter-observer reliability assessed by having two or more observers collect data simultaneously but independently [117]. Plant/bird species richness and biodiversity measurement will employ the well-established Shannon Diversity and Simpson Indexes $[118,119]$ and Evar Evenness Index [116]. Trained graduate students will also make observations of signs of care and the System for Observing Play and Recreation in Communities (SOPARC) [120]. SOPARC provides an assessment of park users' PA levels, gender, activity types, and estimated age and ethnicity groupings as well as information on a park's level of accessibility, usability, supervision, and organization with a high internal correlation between items $(r=0.75)$ [120], and exhibiting high interrater reliability (0.80-0.99) [117]. All nine parks, each of which consists of only one target area due their small size, will be observed twice over one day ( 9 am-2 pm) during randomly scheduled days without rain in summer months, by two raters. INT and CNT parks will be observed at the same time on different days for parallel observations. Signs of care involve observations (presence/ absence) of manmade and natural items in a park and provides a categorical quality rating for each item, which is based on qualitative work in Detroit [114]. Second, we will measure visual greenness and negative visual exposures (signs of disorder) via $360^{\circ}$ images captured along each park perimeter, using a mounted camera (Samsung Gear 360). Images will be used to measure visual greenness, by quantifying pixels of greenery using methods we developed [121]. Images will also be used to assess negative exposures using Marco et al.'s neighbor disorder coding protocol [122], which has shown acceptable ICCs (0.41-0.60) for the mean level of subscales of physical disorder and decay and has also been validated (showing high correlations) with physical audits, police impressions, and neighborhood socioeconomic status. This virtual auditing approach has been validated across several samples $[123,124]$.

We will employ two weighting schemes to create individual-level visual exposures from the park measures. First, we will weight each exposure by the actual contact time spent within view of the park in the oneweek observation time using the GPS data [59], as described previously. Second, we will calculate the percentage of the viewshed occupied by the park, as seen from the participant's home by capturing a $360^{\circ}$ image from the front door of the home location. We will then create weights using these measures, to be applied to each of the visual exposures above.

\section{Neighborhood soundscapes}

Positive and negative auditory exposures will be assessed by acoustic recordings collected by 90 AudioMoth v1.1.0 acoustic loggers (Open Acoustic Devices). Nine devices will be placed at least $100 \mathrm{~m}$ apart randomly in a $500 \mathrm{~m}$ grid around each park, and one device will be placed inside each park. We will record for one week in June, corresponding with Audubon's bird surveys, selecting days to standardize weather conditions. To predict negative auditory exposure, we will calculate environmental noise metrics known to relate to human annoyance, health, and perception including: $\mathrm{L}_{\mathrm{A} \text { eq, } \mathrm{T}}$ (A-weighted equivalent sound level (L) over time); $\mathrm{L}_{\mathrm{Amax}}$ (maximum $\mathrm{A}$-weighted equivalent $\mathrm{L}$ over time); $\mathrm{L}_{\mathrm{A} 10}$ and $\mathrm{L}_{\mathrm{A} 90}$ (A-weighted $\mathrm{L}$ exceeded 10 and $90 \%$ of time); $\mathrm{L}_{\mathrm{A} 10}-\mathrm{LA}_{90}$, LDN (Day-Night average L, where night events receive a $10 \mathrm{~dB}$ penalty); $\mathrm{L}_{\text {DEN }}$ (DayEvening-High equivalency L); roughness (temporal variation in amplitude), and sharpness [125-128]. 
To examine positive auditory exposure, trained staff will count the number and duration of sound categories using observations of spectrograms in Raven Pro software (Cornell University, Ithaca, NY). Sound categories are 'anthropogenic' (e.g., vehicle, people), 'geological' (e.g., wind), and 'biological' (e.g., birdsong). Additionally, we will further categorize bird song to species, in order to generate species richness and diversity of the acoustic community [129]. We will combine the duration/frequency and richness of biological with geological sounds into a metric of positive exposure [130]. Using values of each acoustic exposure metric, we will then predict levels throughout the study area using spatial kriging models [131]. We will extract the positive and negative exposure levels for participants at each time point.

\section{Weather data}

While we restrict data collection to summer months (May-September), weather conditions at the time of data collection and the two weeks prior to data collection may influence both exposures of interest and outcomes. Thus, we will compile daily precipitation and high temperature data for every day during data collection and the two weeks preceding data collection for each time point, from the weather station at Detroit airport (DTW) [132, 133].

\section{Statistical analysis}

Assuming a longitudinal panel design, we will compare INT to CNT at baseline using as appropriate ANOVAF-tests, chi-square tests and non-parametric tests to determine equivalence of potentially confounding physiological and contextual participant characteristics. If substantive differences are found, they will be controlled for in subsequent analyses by regression techniques, guided by the degree of dissimilarity [134]. Equivalence between groups will be assessed on age, sex, ethnicity, employment status, length of residence, marital status, attitudes towards nature, perceived safety, and preexisting health conditions. We will calculate descriptive statistics for all variables at baseline and each postrestoration time point. Likewise, park characteristics will be summarized for the INT and CNT parks for each time point.

We adopt a regression-based approach to multivariable modeling that addresses features of clustering of participants within parks and correlation over time in repeated assessments. Repeated measures ANOVA, or more apropos, generalized linear (mixed) models (GLMM) will be used [135-137]. Denote by $Y_{\text {it }}$ an outcome in the $i$-th participant in the $h$-th park assessed at time $t$. It is assumed that an individual is primarily exposed to one park. Generally, outcomes are assessed at baseline and at least 3 additional time-points, denoted $\mathrm{t}=0,1,2,3$. Our hypotheses concern the expected response: $\mu_{h i t}=\boldsymbol{E}\left(\boldsymbol{Y}_{i t} \mid \mathbf{x}_{i t}, \mathbf{b}_{h i}\right)$.The GLMM is expressed as $g\left(\mu_{h i t}\right)=\mathbf{x}_{i t}^{\prime} \beta+\mathbf{z}_{h t}^{\prime} \mathbf{b}_{h i}$ with link function $g$ appropriate to type of outcome (continuous, categorical, count, ordinal) random effects $\mathbf{b}_{h i}$ to capture serial correlation within participant measures and clustering [138]. The covariates $\mathbf{x}_{\text {hit }}$ are participant characteristics, some of which are time-invariant such as the aforementioned sociodemographic variables; $\mathbf{z}_{h t}$ are characteristics of park $h$ at time $t$. Minimally, the predictor variables are: a single indicator for GROUP, with CNT as referent, three indicators for TIME, corresponding to $t=1,2,3$ with baseline $t=0$ as referent, and GROUP $\times$ TIME interactions. A measure of exposure to environmental stimuli is included in participant characteristics. The GLMM allows us to formulate and test hypotheses on functions of the regression parameters $\beta$, including: i) point-in-time comparison between INT and CNT, e.g., at each followup year; ii) time-averaged comparison between INT and CNT; iii) within group comparison for change over time; and iv) change in INT compared to the corresponding change in CNT via DID. SAS Software v9.4 (Analytics 15.1 or higher) will be used for statistical analyses.

To address missingness in our response data, we will employ strategies for imputation [139]. The techniques described above allow missing at random (MAR). Inverse probability weighting [140] will be investigated to accommodate missing data patterns that are not MAR. To minimize bias in analysis, we will adjust for factors that may be unbalanced between groups and examine the robustness of our conclusions under deviations of model assumptions. Below, we outline specific analyses for each hypothesis to be tested.

\section{Hypothesis 1}

We will separately evaluate average activity counts/minute and average moderate-to-vigorous minutes over the one-week observation period for each of the data collection periods. The predictor of interest is binary: INT versus CNT.

\section{Hypothesis 2}

The primary outcome, 'green PA', will be average activity counts/minute and average moderate-to-vigorous minutes over the one-week observation period while in parks and greenspaces in Detroit, as a subset of all activity.

\section{Hypothesis 3}

We hypothesize there will be an association between PA and the visual and auditory exposures. Instead of a binary predictor of interest, we will use continuous predictors for visual and auditory park exposures. Interaction 
terms between positive and negative exposures will also be assessed, as evidence suggests that negative sounds deplete the restorative benefits of natural sounds, [141] and that parks are often dominated by noise $[45,142]$.

\section{Hypothesis 4}

Each stress outcome will be evaluated separately and treated continuously. We will also explore potential mediators (e.g., PA) by adding each to mixed models as fixed terms, and adjusted mediation and partial correlation coefficients explored. We will adjust for prescription medication history and symptoms of acute illness as potential confounders.

\section{Hypothesis 5}

We will assess relationships with each stress indicator, in turn.

\section{Hypothesis 6}

We hypothesize there will be an association between each stress indicator and these exposures.

\section{Hypothesis 7}

We will compare INT and CNT groups from baseline through three-years post-restoration for changes in CRP and A1C (continuously measured) between INT and CNT groups. We will also consider the inclusion of prescription medication history and symptoms of acute illness as potential confounders.

\section{Hypothesis 8}

We will compare INT and CNT groups from baseline through three-years post-restoration for changes in blood pressure, hip-to-waist ratio and BMI (continuously measured) between INT and CNT groups.

Despite our best effort to recruit and retain a longitudinal panel of participants, we may face problems with attrition higher than the projected attrition rates of $15 \%$ at $\mathrm{t}=1$, another $10 \%$ at $\mathrm{t}=2$, and $5 \%$ at $\mathrm{t}=3$. With these levels, our longitudinal panel becomes unbalanced but valid inference can be made under the assumption that attrition is at random (MAR). We describe another strategy, repeated cross-sections.

By repeated cross-sections we mean a series of independent samples are drawn at the subsequent times $t=$ $1,2,3$ following the initial baseline sample at $t=0$. It could happen that a participant in the baseline sample is also in any of the subsequent samples, but this is at random. With repeated cross-sectional samples, we cannot estimate within participant change in outcomes, which is the key advantage of the longitudinal panel approach. However, we can still assess patterns of change at an aggregate level as explained in the following text.
Consider an outcome $Y_{i t}$ at time $t$ in the $i$-th participant, and the linear model $Y_{i t}=\mathbf{x}_{i t}^{\prime} \beta+\alpha_{i}+\varepsilon_{i t}$ with exogenous covariates $\mathbf{x}_{i t}, t=0,1,2,3$. We aggregate each sample into $C$ cohorts defined as participants who share common characteristics such as age, sex, neighborhood park, etc. Aggregation of participants to the cohort level $c$ replaces the model by the cohort model $\bar{Y}_{c t}=\overline{\mathbf{x}}_{c t}{ }_{t} \beta$ $+\bar{\alpha}_{c}+\bar{\varepsilon}_{c t}, c=1, \ldots, C, t=0,1,2$, 3. (Bar notation refers to averages over participants within cohort/time). Our observed data become a pseudo-panel of repeated observations on cohorts over time, and estimation of differences between INT and CNT cohorts could be compared over time, although the cohorts are not comprised of the same participants from one time point to the other. Some technical issues will need to be addressed to ensure a consistent estimator of $\beta$ [143-146].

\section{Discussion}

At the time this investigation was initiated, to our knowledge no experimental study has examined the visual and auditory exposures to greenspace to illuminate the twinned effects on PA and stress, and downstream cardio-metabolic health. Previous experimental studies have focused on the addition of conventional park equipment and infrastructure, which tend to be very expensive interventions. Additionally, we apply a rigorous measurement protocol that uses device-based/objective measurement of both exposures and outcomes to evaluate the effects of the intervention on PA, stress and cardio-metabolic outcomes. Further, and importantly, this study involves measurement of individual-level variation in positive and negative exposures using geospatial techniques, rather than assuming equal exposure among all nearby residents. A recent report from WHO on the effectiveness of greenspace interventions on health noted that such interventions are promising avenues to improve physical and mental health in cities, particularly in low-income neighborhoods, although evidence is still needed to confirm the effect of urban greenspace interventions in deprived populations. This study addresses several recommendations from the report. The effectiveness of those recommendations is yet to be determined in a manner that will allow researchers and practitioners to provide better evidence-informed policies and practices in low-income urban neighborhoods.

\footnotetext{
Abbreviations

A1C: Glycated hemoglobin A1C; BMI: Body Mass Index; CNT: Control park neighborhoods in our study; CRP: C-reactive protein; CVD: Cardiovascular disease; DBS: Dried blood spots; DID: Difference-In-Differences; DPRD: City of Detroit Parks and Recreation Department; EF: Effect size; FLASHE: Family Life, Activity, Sun, Health, and Eating; GLMM: Generalized Linear (Mixed) Models; GPS: Global positioning system; ICC: Intra-class correlation; INT: Intervention park neighborhoods in our study; IRB: Institutional Review Board; MAR: Missing at random; NCl: National Cancer Institute; NIH: National Institutes of Health; NR-6: Nature-relatedness, 6 question; PA: Physical activity;
} 
ROBINS-I: Risk Of Bias In Non-Randomized Studies of Interventions; SOPARC: System for Observing Play And Recreation in Communities; StAND: Study of Active Neighborhoods in Detroit; WHO: World Health Organization

\section{Acknowledgements}

The authors thank the participants, field staff under the leadership of Dr. Ventra Asana, and community organizations and churches which support this study. Additionally, the authors thank the Audubon intervention staff, Diane Cheklich and Ava Landgraf, and Detroit Parks and Recreation staff, Meagan Elliott, Juliana Fulton, and Barry Burton. Student/postdoc assistants include Claudia Allou, Katie McKee, Ben Dougherty, Cordelia Martin-lpke, and Elizabeth Shewark. The authors also thank Dr. Kimberly Clevenger for her assistance with the survey modules and training field staff and the National Park Service Natural Sounds and Night Skies division and Cornell Lab of Ornithology for lending acoustic equipment.

\section{Authors' contributions}

ALP, KAP, TH, JG, RH, TM and RB helped conceive of the study. KAP and TH directly help with training and data acquisition. JG will lead data analysis. ALP is principal investigator and conceived of the study and its design, procured the funding, directs data acquisition and critically revised the manuscript. All authors except VB helped procure the funding. All authors critically revised the manuscript, read and approved the final manuscript.

\section{Funding}

This study was funded by the National Cancer Institute (NCI) of the National Institutes of Health (NIH) 1R01CA239197-01, the Detroit Medical Center, Michigan State University's Clinical Translational Science Initiative, the Vice President for Research and Graduate Studies and the Provost Undergraduate Research Initiative. Salary for TH is provided by the Negaunee Foundation.

\section{Availability of data and materials}

Not applicable.

\section{Ethics approval and consent to participate}

The study was approved by the Michigan State University's Institutional Review Board (IRB Approval \#STUDY00000587; date 03/21/2019). Informed consent will be obtained in writing from all participants.

\section{Consent for publication}

Not applicable.

\section{Competing interests}

The authors declare that they have no competing interests.

\section{Author details}

'Department of Geography, Environment and Spatial Sciences, Michigan State University, 673 Auditorium Road, East Lansing, MI 48824, USA. ${ }^{2}$ Department of Kinesiology, Michigan State University, 27R Intramural Rec Sports- Circle, 308 West Circle Drive, East Lansing, MI 48824, USA. ${ }^{3}$ Department of Epidemiology and Biostatistics, Michigan State University, 909 Wilson Road, Room B601, East Lansing, MI 48824, USA. ${ }^{4}$ Department of Anthropology, Northwestern University, 1810 Hinman Ave, Evanston, IL 60208, USA. ${ }^{5}$ Department of Biology, Carleton University, 209 Nesbitt Biology Building, Ottawa, ON K1S 5B6, Canada. ${ }^{6}$ Centre for Public Health, Queen's University Belfast, University Road, Belfast BT7 1NN, Northern Ireland, UK.

\section{Received: 6 April 2020 Accepted: 15 April 2020}

\section{Published online: 07 May 2020}

\section{References}

1. Cohen S, Janicki-Deverts D, Doyle WJ, Miller GE, Frank E, Rabin BS, et al. Chronic stress, glucocorticoid receptor resistance, inflammation, and disease risk. Proc Natl Acad Sci U S A. 2012;109(16):5995-9..

2. Jin C, Flavell RA. Innate sensors of pathogen and stress: linking inflammation to obesity. J Allergy Clin Immunol. 2013;132(2):287-94.

3. Johnson AR, Milner JJ, Makowski L. The inflammation highway: metabolism accelerates inflammatory traffic in obesity. Immunol Rev. 2012;249(1):218-38.

4. Despres JP. Abdominal obesity and cardiovascular disease: is inflammation the missing link? Can J Cardiol. 2012;28(6):642-52.
5. Slavich GM, Irwin MR. From stress to inflammation and major depressive disorder: a social signal transduction theory of depression. Psychol Bull. 2014;140(3):774-815.

6. de Heredia FP, Gomez-Martinez S, Marcos A. Obesity, inflammation and the immune system. Proc Nutr Soc. 2012;71(2):332-8.

7. Banerjee M, Saxena M. Interleukin-1 (IL-1) family of cytokines: role in type 2 diabetes. Clin Chimica Acta. 2012;413(15-16):1163-70.

8. Ludwig J, Sanbonmatsu L, Gennetian L, Adam E, Duncan GJ, Katz LF, et al. Neighborhoods, obesity, and diabetes--a randomized social experiment. N Engl J Med. 2011;365(16):1509-19.

9. Moore CJ, Cunningham SA. Social position, psychological stress, and obesity: a systematic review. J Acad Nutr Diet. 2012;112(4):518-26.

10. Boehmer TK, Hoehner CM, Deshpande AD, Brennan Ramirez LK, Brownson RC. Perceived and observed neighborhood indicators of obesity among urban adults. Int J Obes. 2007:31(6):968-77.

11. Miller G, Chen E, Cole SW. Health psychology: developing biologically plausible models linking the social world and physical health. Annu Rev Psychol. 2009;60:501-24.

12. Scott KA, Melhorn SJ, Sakai RR. Effects of chronic social stress on obesity Curr Obes Rep. 2012;1(1):16-25.

13. de Kock A, Malan L, Hamer M, Cockeran M, Malan NT. Defensive coping and renovascular disease risk - adrenal fatigue in a cohort of Africans and Caucasians: the SABPA study. Physiol Behav. 2015;147:213-9.

14. McDade TW, Hoke M, Borja JB, Adair LS, Kuzawa C. Do environments in infancy moderate the association between stress and inflammation in adulthood? Initial evidence from a birth cohort in the Philippines. Brain Behav Immun. 2013;31:23-30.

15. Cawley J, Meyerhoefer C, Biener A, Hammer M, Wintfeld N. Savings in Medical Expenditures Associated with reductions in body mass index among US adults with obesity, by diabetes status. Pharmacoeconomics. 2015;33(7):707-22.

16. Chetty R, Stepner M, Abraham S, Lin S, Scuderi B, Turner N, et al. The association between income and life expectancy in the United States, 20012014. JAMA. 2016;315(16):1750-66.

17. CDC. Michigan: State nutrition, physical activity and obesity profile. Atlanta: Centers for Disease Control and Prevention; 2016.

18. Weissman J, Pratt LA, Miller EA, Parker JD. Serious psychological distress among adults: United States, 2009-2013. Washington: US Department of Health and Human Services, National Center for Health Statistics; 2015. Contract No.: 203.

19. Eskandari F, Sternberg EM. Neural-immune interactions in health and disease. Ann N Y Acad Sci. 2002;966:20-7.

20. Juster RP, McEwen BS, Lupien SJ. Allostatic load biomarkers of chronic stress and impact on health and cognition. Neurosci Biobehav Rev. 2010;35(1):2-16

21. Eyre HA, Papps E, Baune BT. Treating depression and depression-like behavior with physical activity: an immune perspective. Front Psychiatry. 2013;4:3.

22. Wolff-Hughes DL, Fitzhugh EC, Bassett DR, Churilla JR. Total activity counts and Bouted minutes of moderate-to-vigorous physical activity: relationships with Cardiometabolic biomarkers using 2003-2006 NHANES. J Phys Act Health. 2015;12(5):694-700.

23. Thompson Coon J, Boddy K, Stein K, Whear R, Barton J, Depledge MH. Does participating in physical activity in outdoor natural environments have a greater effect on physical and mental wellbeing than physical activity indoors? A systematic review. Environ Sci Technol. 2011;45(5):1761-72.

24. MacLean PS, Wing RR, Davidson T, Epstein L, Goodpaster B, Hall KD, et al. $\mathrm{NIH}$ working group report: innovative research to improve maintenance of weight loss. Obesity (Silver Spring). 2015;23(1):7-15.

25. Peters A, McEwen BS. Stress habituation, body shape and cardiovascular mortality. Neurosci Biobehav Rev. 2015;56:139-50.

26. Hartig T, Kahn PH. Living in cities, naturally. Science. 2016;352(6288):938-40.

27. WHO. Urban Green Spaces and Health. A review of the evidence. Copenhagen: Urban green spaces and health. Copenhagen: WHO Regional Office for Europe; 2016. p. 2016.

28. de Brito JN, Pope ZC, Mitchell NR, Schneider IE, Larson JM, Horton TH, Pereira MA. Changes in Psychological and Cognitive Outcomes after Green versus Suburban Walking: A Pilot Crossover Study. Int J Environ Resour Public Health. 2019;16(16):2894.

29. Olafsdottir G, Cloke P, Vogele C. Place, green exercise and stress: an exploration of lived experience and restorative effects. Health Place. 2017:46: 358-65. 
30. Pretty J, Peacock J, Sellens M, Griffin M. The mental and physical health outcomes of green exercise. Int J Environ Health Res. 2005;15:319-37.

31. Koselka EPD, Weidner LC, Minasov A, Berman MG, Leonard WR, Santoso MV, et al. Walking Green: Developing an Evidence Base for Nature Prescriptions. Int J Environ Res Public Health. 2019;16(22):4338.

32. Cox DTC, Shanahan DF, Hudson HL, Plummer KE, Siriwardena GM, Fuller RA, et al. Doses of Neighborhood Nature: The Benefits for Mental Health of Living with Nature. BioScience. 2017;67(2):147-55.

33. Shanahan DF, Bush R, Gaston KJ, Lin BB, Dean J, Barber E, et al. Health benefits from nature experiences depend on dose. Sci Rep. 2016;6:28551.

34. Lachowycz K, Jones AP. Greenspace and obesity: a systematic review of the evidence. Obes Rev. 2011;12(5):e183-e9.

35. Pearson AL, Bentham G, Day P, Kingham S. Associations between neighbourhood environmental characteristics and obesity and related behaviours among adult new Zealanders. BMC Public Health. 2014;14(1):553.

36. Tilt JH, Unfried TM, Roca B. Using objective and subjective measures of neighborhood greenness and accessible destinations for understanding walking trips and BMI in Seattle, Washington. Am J Health Promotion. 2007; 21(4 Suppl):371-9.

37. Bell JF, Wilson JS, Liu GC. Neighborhood greenness and 2-year changes in body mass index of children and youth. Am J Prev Med. 2008;35(6):547-53.

38. Lovasi GS, Jacobson JS, Quinn JW, Neckerman KM, Ashby-Thompson MN, Rundle A. Is the environment near home and school associated with physical activity and adiposity of urban preschool children? J Urban Health. 2011:88(6):1143-57.

39. Lovasi GS, Bader MD, Quinn J, Neckerman K, Weiss C, Rundle A. Body mass index, safety hazards, and neighborhood attractiveness. Am J Prev Med. 2012;43(4):378-84.

40. Pereira G, Christian H, Foster S, Boruff B, Bull F, Knuiman M, et al. The association between neighborhood greenness and weight status: an observational study in Perth Western Australia. Environ Health. 2013;12:49.

41. Michimi A, Wimberly MC. Natural environments, obesity, and physical activity in nonmetropolitan areas of the United States. J Rural Health. 2012; 28(4):398-407.

42. Stevens J, Murray DM, Catellier DJ, Hannan PJ, Lytle LA, Elder JP, et al. Design of the trial of activity in adolescent girls (TAAG). Contemp Clin Trials. 2005;26(2):223-33.

43. Pearson AL, Clevenger K, Horton TH, Gardiner J, Asana V, Dougherty B, et al. Feelings of safety during daytime walking: Associations with mental health, physical activity and cardiometabolic health in two high vacancy, lowincome neighborhoods in Detroit, Michigan. PLoS ONE. in review.

44. Des Jarlais DC, Lyles C, Crepaz N, TREND Group. Improving the Reporting Quality of Nonrandomized Evaluations of Behavioral and Public Health Interventions: The TREND Statement. Am J Public Health. 2004;94(3):361-6.

45. Buxton RT, McKenna MF, Mennitt D, Fistrup K, Crooks K, Angeloni L, et al. Noise pollution is pervasive in U.S. protected areas. Science. 2017;356:531-3.

46. Huang TT, Wyka KE, Ferris EB, Gardner J, Evenson KR, Tripathi D, et al. The physical activity and redesigned community spaces (PARCS) study: protocol of a natural experiment to investigate the impact of citywide park redesign and renovation. BMC Public Health. 2016;16(1):1160.

47. Roe J, Ward Thompson C, Aspinall P, Brewer M, Duff E, Miller D, et al. Green space and stress: evidence from cortisol measures in deprived urban communities. Int J Environ Res Public Health. 2013;10(9):4086-103.

48. Hedges L. Effect sizes in cluster-randomized designs. J Educ Behav Stat. 2007;32(4):341-70

49. Kul S, Vanhaecht K, Panella M. Intraclass correlation coefficients for cluster randomized trials in care pathways and usual care: hospital treatment for heart failure. BMC Health Serv Res. 2014;14:84.

50. Parker DR, Evangelou E, Eaton CB. Intraclass correlation coefficients for cluster randomized trials in primary care: the cholesterol education and research trial (CEART). Contemp Clin Trials. 2005;26(2):260-7.

51. Smeeth L, Ng E. Intraclass correlation coefficients for cluster randomized trials in primary care: data from the MRC trial of the assessment and Management of Older People in the community. Control Clin Trials. 2002; 23(4):409-21.

52. Garvin EC, Cannuscio CC, Branas CC. Greening vacant lots to reduce violent crime: a randomised controlled trial. Inj Prev. 2013;19(3):198-203.

53. Sterne JA, Hernan MA, Reeves BC, Savovic J, Berkman ND, Viswanathan M, et al. ROBINS-I: a tool for assessing risk of bias in non-randomised studies of interventions. BMJ. 2016:355:14919.
54. Oreskovic N, Huang T, Moon J. Integrating mHealth and systems science: a combination approach to prevent and treat chronic health conditions. JMIR mHealth uHealth. 2015;3(2):e62

55. Freedson P, Melanson E, Sirard J. Calibration of the Computer Science and Applications, Inc. accelerometer. Med Sci Sports Exerc. 1998;30:777-81.

56. Matthews CE, Chen KY, Freedson PS, Buchowski MS, Beech BM, Pate RR, et al. Amount of time spent in sedentary behaviors in the United States, 2003-2004. Am J Epidemiol. 2008;167(7):875-81.

57. Sasaki JE, John D, Freedson PS. Validation and comparison of ActiGraph activity monitors. J Sci Med Sport. 2011;14:411-6.

58. Matthews C, Ainsworth B, RWT, Bassett D. Sources of variance in daily physical activity levels as measured by an accelerometer. Med Sci Sports Exerc. 2002;34:1376-81.

59. Humphreys DK, Panter J, Sahlqvist S, Goodman A, Ogilvie D. Changing the environment to improve population health: a framework for considering exposure in natural experimental studies. J Epidemiol Community Health. 2016;70(9):941-6.

60. Nutsford D, Reitsma F, Pearson AL, Kingham S. Personalising the viewshed: visibility analysis from the human perspective. Appl Geogr. 2015;62:1-7.

61. Nutsford D, Pearson AL, Kingham S, Reitsma F. Residential exposure to visible blue space (but not green space) associated with lower psychological distress in a capital city. Health Place. 2016;39:70-8.

62. Nater UM, Skoluda N, Strahler J. Biomarkers of stress in behavioural medicine. Curr Opin Psychiatry. 2013;26(5):440-5.

63. Thompson CW, Roe J, Aspinall P, Mitchell R, Clow A, Miller D. More green space is linked to less stress in deprived communities: evidence from salivary cortisol patterns. Landscape Urban Plan. 2012;105(3):221-9.

64. Edwards C. Sixty years after Hench--corticosteroids and chronic inflammatory disease. J Clin Endocrinol Metab. 2012;97(5):1443-51.

65. Miller GE, Cohen S, Ritchey AK. Chronic psychological stress and the regulation of pro-inflammatory cytokines: a glucocorticoid-resistance model. Health Psychology. 2002;21(6):531-41.

66. Miller GE, Chen E, Zhou ES. If it goes up, must it come down? Chronic stress and the hypothalamic-pituitary-adrenocortical axis in humans. Psychol Bull. 2007;133(1):25-45.

67. Squires EC, McClure HH, Martinez CR Jr, Eddy JM, Jimenez RA, Isiordia LE, et al. Diurnal cortisol rhythms among Latino immigrants in Oregon, USA. J Physiol Anthropol. 2012;31:19.

68. Salimetrics, editor. Saliva Collecting and Handling Advice. 3 ed. Carlsbad: Salimetrics, LLC and SalivaBio, LLC; 2013. p. 1-18.

69. Hellhammer DH, Wust S, Kudielka BM. Salivary cortisol as a biomarker in stress research. Psychoneuroendocrinology. 2009;34(2):163-71.

70. Nyberg CH. Diurnal cortisol rhythms in Tsimane' Amazonian foragers: new insights into ecological HPA axis research. Psychoneuroendocrinology. 2012; 37(2):178-90.

71. Salimetrics. Expanded Range High Sensitivity Salivary Cortisol Enzyme Immunoassay Kit. In: Salimetrics, editor. State College: Salimetrics; 2017.

72. Ader DN. Developing the patient-reported outcomes measurement information system (PROMIS). Med Care. 2007:45(5):S1-2.

73. Cella D, Yount S, Rothrock N, Gershon R, Cook K, Reeve B, et al. The patientreported outcomes measurement information system (PROMIS): progress of an $\mathrm{NIH}$ roadmap cooperative group during its first two years. Med Care. 2007:45(5 Suppl 1):S3-S11.

74. Cohen S, Kamarck T, Mermelstein R. A global measure of perceived stress. J Health Soc Behav. 1983;24(4):385-96.

75. Khalili R, Sirati Nir M, Ebadi A, Tavallai A, Habibi M. Validity and reliability of the Cohen 10-item perceived stress scale in patients with chronic headache: Persian version. Asian J Psychiatr. 2017;26:136-40.

76. Baik SH, Fox RS, Mills SD, Roesch SC, Sadler GR, Klonoff EA, et al. Reliability and validity of the perceived stress Scale-10 in Hispanic Americans with English or Spanish language preference. J Health Psychol. 2019;24(5):628-39.

77. Tang E, Ekundayo O, Peipert JD, Edwards N, Bansal A, Richardson C, et al. Validation of the patient-reported outcomes measurement information system (PROMIS)-57 and -29 item short forms among kidney transplant recipients. Qual Life Res. 2019;28(3):815-27.

78. WHO. Circumference and Waist-Hip Ratio 2011 [Available from: http://apps. who.int/iris/bitstream/10665/44583/1/9789241501491_eng.pdf. Accessed 17 Mar 2020.

79. Cifu AS, Davis AM. Prevention, detection, evaluation, and management of high blood pressure in adults. JAMA. 2017;318(21):2132-4. 
80. International Diabetes Federation Guideline Development G. Global guideline for type 2 diabetes. Diabetes Res Clin Pract. 2014;104(1):1-52.

81. Copeland WE, Shanahan L, Worthman C, Angold A, Costello EJ. Cumulative depression episodes predict later $\mathrm{C}$-reactive protein levels: a prospective analysis. Biol Psychiatry. 2012;71(1):15-21.

82. Kuo HK, Yen CJ, Chang $\mathrm{CH}$, Kuo CK, Chen JH, Sorond F. Relation of Creactive protein to stroke, cognitive disorders, and depression in the general population: systematic review and meta-analysis. Lancet Neurol. 2005;4(6): 371-80.

83. Liukkonen $\mathrm{T}$, Silvennoinen-Kassinen $\mathrm{S}$, Jokelainen J, Rasanen $\mathrm{P}$, Leinonen $\mathrm{M}$, Meyer-Rochow VB, et al. The association between C-reactive protein levels and depression: results from the northern Finland 1966 birth cohort study Biol Psychiatry. 2006;60(8):825-30.

84. McDade TW, Borja JB, Kuzawa CW, Perez TL, Adair LS. C-reactive protein response to influenza vaccination as a model of mild inflammatory stimulation in the Philippines. Vaccine. 2015;33(17):2004-8.

85. Vindevogel S, Van Parys H, De Schryver M, Broekaert E, Derluyn I. A mixedmethods study of former child Soldiers' transition trajectories from military to civilian life. J Adolescent Res. 2017;32(3):346-70.

86. Ridker PM. High-sensitivity C-reactive protein as a predictor of all-cause mortality: implications for research and patient care. Clin Chem. 2008;54(2):234-7.

87. Ford DE, Erlinger TP. Depression and C-reactive protein in US adults: data from the third National Health and nutrition examination survey. Arch Intern Med. 2004;164(9):1010-4.

88. Maes M, Berk M, Goehler L, Song C, Anderson G, Galecki P, et al. Depression and sickness behavior are Janus-faced responses to shared inflammatory pathways. BMC Med. 2012;10:66.

89. Godbout JP, Glaser R. Stress-induced immune dysregulation: implications for wound healing, infectious disease and cancer. J Neurolmmune Pharmacol. 2006; (4):421-7

90. Pepys MB, Hirschfield GM. C-reactive protein: a critical update. J Clin Invest. 2003;111(12):1805-12.

91. Herbert TB, Cohen S. Stress and immunity in humans: a meta-analytic review. Psychosom Med. 1993;55(4):364-79.

92. Glaser R, Kiecolt-Glaser J. How stress damages immune system and health. Discov Med. 2005:5(26):165-9.

93. Ramos-Nino ME. The role of chronic inflammation in obesity-associated cancers. ISRN Oncol. 2013;2013:697521.

94. Parente V, Hale L, Palermo T. Association between breast cancer and allostatic load by race: National Health and nutrition examination survey 1999-2008. Psycho-oncology. 2013;22(3):621-8.

95. Mcdade TW, Williams S, Snodgrass JJ. What a drop can do: dried blood spots as a minimally invasive method for integrating biomarkers into population-based research. Demography. 2007;44(4):899-925.

96. Ostler MW, Porter JH, Buxton OM. Dried blood spot collection of health biomarkers to maximize participation in population studies. J Vis Exp. 2014; 83:e50973.

97. McDade TW, Burhop J, Dohnal J. High-sensitivity enzyme immunoassay for C-reactive protein in dried blood spots. Clin Chem. 2004;50(3):652-4.

98. Saelens BE, Sallis JF, Black JB, Chen D. Neighborhood-based differences in physical activity: an environment scale evaluation. Am J Public Health. 2003; 93:1552-8.

99. Forsyth A, Oakes JM, Schmitz KH. Test-retest reliability of the twin cities walking survey. J Phys Act Health. 2009;6(1):119-31.

100. Schroeder P, Wilbur M. 2012 National survey of bicyclist and pedestrian attitudes and behavior: Findings report. Washington, DC: National Highway Traffic Safety Administration; 2013. Contract No.: DOT HS 811841 B.

101. Ramos H, Gosse M, Pritchard P, Radice M, Grant J, Shakotko P, et al. How Haligonians perceive neighborhood change. Toronto: NCRP Research Symposium Presentation; 2016

102. Prouse V, Grant J, Ramos H, Radice M. Assessing neighbourhood change: Gentrification and suburban decline in a mid-sized city. Halifx: School of Planning, Dalhousie University; 2015.

103. National Eye Institute. Vision Function Questionnaire 25, Self-Administered Format. 2000.

104. Audiometry Questionnaire (AUQ). 2017-2018 National Heath and Nutrition Examination Survey. 2018.

105. Cantor D, Coa K, Crystal-Mansour S, Davis T, Dipko S, Sigman R. Health Information National Trends Study (HINTS) 2007 Final Report. Bethesda: National Cancer Institute; 2009.
106. NHANES. NHANES 2017-2018 Questionnaire Instruments CDC/National Center for Health Statistics. 2018.

107. NHANES. Dietary Screener Questionnaires (DSQ) in the NHANES 2009-10: DSQ. 2010.

108. Nebeling LC, Hennessy E, Oh AY, Dwyer LA, Patrick H, Blanck HM, et al. The FLASHE study: survey development, dyadic perspectives, and participant characteristics. Am J Prev Med. 2017;52(6):839-48.

109. Nisbet EK, Zelenski JM. The NR-6: a new brief measure of nature relatedness. Front Psychol. 2013;4:813.

110. Pearson AL, Breetzke GD. The association between the fear of crime, and mental and physical wellbeing in New Zealand. Soc Indic Res. 2014;119(1): 281-94.

111. Roman CG, Chalfin A. Fear of walking outdoors: a multilevel ecologic analysis of crime and disorder. Am J Prev Med. 2008;34(4):306-12.

112. Schweitzer JH, Kim JW, Mackin JR. The impact of the built environment on crime and fear of crime in urban neighborhoods. J Urban Technol. 1999;6: 59-73.

113. Lapham SC, Cohen DA, Han B, Williamson S, Evenson KR, McKenzie TL, et al. How important is perception of safety to park use? A four-city survey. Urban Stud. 2016:53(12):2624-36.

114. Sampson N, Nassauer J, Schulz A, Hurd K, Dorman C, Ligon K. Landscape care of urban vacant properties and implications for health and safety: lessons from photovoice. Health Place. 2017;46:219-28.

115. Wheeler BW, Lovell R, Higgins SL, White MP, Alcock I, Osborne NJ, et al. Beyond greenspace: an ecological study of population general health and indicators of natural environment type and quality. Int J Health Geogr. 2015;14:17.

116. Weiher E, Keddy PA. Relative abundance and evenness patterns along diversity and biomass gradients. Oikos. 1999;87(2):355-61.

117. Cohen DA, Setodji C, Evenson KR, Ward P, Lapham S, Hillier A, et al. How much observation is enough? Refining the administration of SOPARC. J Phys Act Health. 2011:8(8):1117-23.

118. Shannon C. A mathematical theory of communication. Bell Syst Tech J. 1948;27:79-423 623-56.

119. Simpson EH. Measurement of species diversity. Nature. 1949;163:688.

120. McKenzie TL, Cohen DA, Sehgal A, Williamson S, Golinelli D. System for observing play and recreation in communities (SOPARC): reliability and feasibility measures. J Phys Act Health. 2006;3(1):S208-S22.

121. Pearson A, Bottomley R, Chambers T, Thornton L, Stanley J, Smith M, et al. Measuring blue space visibility and 'blue recreation' in the everyday lives of children in a Capital City. Int J Environ Res Public Health. 2017:14(6):563.

122. Marco M, Gracia E, Martín-Fernández M, López-Quílez A. Validation of a google street view-based neighborhood disorder observational scale. J Urban Health. 2017;94(2):190-8.

123. Mooney SJ, Bader MD, Lovasi GS, Neckerman KM, Teitler JO, Rundle AG. Validity of an ecometric neighborhood physical disorder measure constructed by virtual street audit. Am J Epidemiol. 2014;180(6):626-35.

124. Rundle AG, Bader MDM, Richards CA, Neckerman KM, Teitler JO. Using google street view to audit neighborhood environments. Am J Prev Med. 2011;40(1):94-100.

125. World Health Organization. Burden of disease from environmental noise: quantification of healthy life years lost in Europe. Copenhagen: World Health Organisation, Regional Office for Europe, Bonn, and European Commission Joint Research Centre; 2011. p. 106.

126. Brocolini L, Lavandier C, Quoy M, Ribeiro C. Measurements of acoustic environments for urban soundscapes: choice of homogeneous periods, optimization of durations, and selection of indicators. J Acoust Soc Am. 2013;134(1):813-21.

127. Schultz TJ. Synthesis of social surveys on noise annoyance. J Acoust Soc Am. 1978;64(2):377-405

128. Rychtáriková M, Vermeir G. Soundscape categorization on the basis of objective acoustical parameters. Appl Acoust. 2013;74(2):240-7.

129. Buxton R, McKenna M, Clapp M, Meyer E, Angeloni L, Crooks K, et al. Efficacy of extracting indices from large-scale acoustic recordings to monitor biodiversity. Conserv Biol. 2018:32:1174-84.

130. Lavandier C, Defréville B. The contribution of sound source characteristics in the assessment of urban soundscapes. Acta Acustica united with Acustica. 2006;92(6):912-21.

131. Aumond P, Can A, Mallet V, De Coensel B, Robeiro C, Botteldooren D, et al. Kriging-based spatial interpolation from measurements for sound level mapping in urban areas. J Acoust Soc Am. 2018;143:2847. 
132. Menne MJ, Durre I, Korzeniewski B, McNeal S, Thomas K, Yin X, et al. In: Center NNCD, editor. Global historical climatology network - daily (GHCNdaily), version 3; 2012.

133. Menne MJ, Durre I, Vose RS, Gleason BE, Houston TG. An overview of the global historical climatology network-daily database. J Atmos Oceanic Techol. 2012;29:897-910.

134. Altman D. Comparability of randomised groups. Statistician. 1985;34:125-36.

135. Gardiner J, Luo Z, Roman L. Fixed effects, random effects and GEE: what are the differences? Stat Med. 2009:28(2):221-39.

136. McCulloch C, Searle S. Generalized, linear, and mixed models. New York: Wiley \& Sons; 2001.

137. Roman L, Gardiner J, Lindsay J, Moore J, Luo Z, Baer L, et al. Alleviating perinatal depressive symptoms and stress: a nurse-community health worker randomized trial. Arch Womens Mental Health. 2009;12(6):379-91.

138. Verbeke G, Molenberghs G. Linear mixed models for longitudinal data. New York: Springer-Verlag; 2000.

139. Little R. Modeling the drop-out mechanism in repeated-measures studies. J Am Stat Assoc. 1995;90(431):1112-21.

140. Wooldridge J. Econometric analysis of cross section and panel data. 2nd edition ed. Cambridge: MIT Press; 2010.

141. Rådsten-Ekman M, Axelsson Ö, Nilsson ME. Effects of sounds from water on perception of acoustic environments dominated by road-traffic noise. Acta Acustica united with Acustica. 2013;99(2):218-25.

142. Nilsson ME, Berglund B. Soundscape quality in suburban green areas and city parks. Acta Acust United Acust. 2006;92(6):903-11.

143. Cameron AC, Trivedi PK. Microeconomics: methods and applications. New York: Cambridge University Press; 2005.

144. Stevens J, Murray DM, Catellier DJ, Hannan PJ, Lytele LA, Elder JP, et al. Design of a trial of activity in adolescent girls (TAAG). Contemp Clin Trials. 2005:26:223-33.

145. Rafferty A, Walthery P, King-Hele S. Analysing change over time: repeated cross-sectional and longitudinal survey data: University of Essex and University of Manchester; 2015.

146. Verbeek M. Pseudo-Panels and Repeated Cross-Sections. In: Matyas L, Sevestre P, editors. The Econometrics of Panel Data. Berlin: Springer-Verlag; 2008

\section{Publisher's Note}

Springer Nature remains neutral with regard to jurisdictional claims in published maps and institutional affiliations.

Ready to submit your research? Choose BMC and benefit from:

- fast, convenient online submission

- thorough peer review by experienced researchers in your field

- rapid publication on acceptance

- support for research data, including large and complex data types

- gold Open Access which fosters wider collaboration and increased citations

- maximum visibility for your research: over $100 \mathrm{M}$ website views per year

At $\mathrm{BMC}$, research is always in progress.

Learn more biomedcentral.com/submissions 